\title{
ALGUMAS CONSIDERAÇÕES SOBRE A FANTASIA EM FREUD E LACAN' ${ }^{1}$
}

\section{Alessandra Fernandes Carreira}

Resumo: Este artigo discute algumas considerações de Freud e Lacan a respeito da fantasia, salientando a sua gênese e função para o sujeito. Para isso, retoma os três tempos da fantasia trazidos por Freud e as duas operações lógicas, que constituem o articulador entre o sujeito e o "objeto a", presentes no matema da fantasia elaborado por Lacan, a saber: a alienação e a separação.

Palavras-chave: Fantasia. Freud, Sigmund, 1856-1939. Lacan, Jacques, 1901-1981.

"Quem, entre o incêndio da alma em que o ser periga,

Me deixou só no fogo e no torpor?

Quem fez a fantasia minha amiga, Negando o fruto e emurchecendo a flor?

Ninguém ou o Fado, e a fantasia siga

A seu infiel e irreal sabor...

Quem me dispôs para o que não pudesse?

Quem me fadou para o que não conheço

Na teia do real que ninguém tece?”

"Glosa”, Fernando Pessoa

1 Esse artigo deriva de uma pesquisa de pós-doutorado acerca das relações entre autoria e fantasia, supervisionada pela Profa. Dra. Nina Virgínia de Araújo Leite, junto ao Instituto de Estudos da Linguagem - IEL/ Universidade Estadual de Campinas - UNICAMP. 


\section{E a fantasia siga}

A fantasia ${ }^{2}$ é um conceito importante no escopo da teoria psicanalítica desde Freud, que bem cedo se deparou, no tratamento das histéricas, com uma realidade que não pode ser considerada fatual, mas sim psíquica. Embora a princípio ele também tenha caído no engodo de tomar as cenas de sedução, nas quais suas pacientes se apresentavam como forçosamente submetidas ao desejo do Outro, como fatos, ele pôde localizar aí a criação de um sujeito, que traumatiza e faz sintoma.

É justamente em função de seu caráter traumático que a verossimiIhança dessas cenas, narradas pelas histéricas freudianas, não pôde ser tomada como inverdade, mas como ficção que dá estrutura à verdade. Tal verdade é reiterada na enunciação que subsiste nos enunciados dessa ficção e os engendra, fixando o sujeito em um instante eterno e inenarrável: instante em que ele (não) é tomado pelo desejo do Outro.

Dessa forma, a reconstrução da fantasia durante uma psicanálise só pode se dar na gramática que predica o sujeito em suas relações com o desejo do Outro, ou seja, enquanto estrutura lógica que subjaz aos ditos do sujeito e aponta para sua posição diante desse desejo.

A fim de refletir um pouco a respeito dessa estrutura, esse artigo retomará algumas das considerações de Freud e Lacan a respeito da fantasia, focalizando-se principalmente em sua gênese e em sua função para o sujeito.

\section{O incêndio da alma}

Comecemos abordando Freud, especificamente seu texto "Uma criança é espancada",de 1919, no qual ele aborda a fantasia na neurose, privilegiando a de espancamento, pois a notou recorrente em seus pacientes, sobretudo nos do sexo feminino. Nessa ocasião, embora ele deixe clara a obscuridade da fantasia em termos teóricos, aponta algumas de suas principais características, que serão retomadas a seguir.

A primeira delas é a presença de uma satisfação autoerótica, ou seja, a geração de prazer ao próprio sujeito que cria a fantasia. Tal satisfação remete a um traço primário de perversão, ao qual o sujeito está fixado e que se destacou prematuramente da sexualidade infantil, caracterizada por uma perversidade polimorfa (Freud, 1905/1980).

Vale lembrar que, para Freud (1905/1980), a perversão é um dos processos típicos da vida sexual da criança, sendo inicialmente levada para a relação com o objeto de amor incestuoso e, posteriormente, permanecendo como herdeiro da carga de libido do Complexo de Édipo que sucum-

2 Embora, no português, seja corrente tanto o uso do significante fantasma, quanto do significante fantasia, para a tradução do francês fantasme, optei pelo segundo seguindo as indicações de Gerbase (1987). 
biu ao recalque. No caso da neurose, a perversão é interrompida, restando apenas um de seus traços, ao qual o sujeito se fixa e que permanece ao fundo de seu desenvolvimento sexual, retirando-lhe perpetuamente uma determinada quantidade de energia. Trata-se, assim, de um traço que não se desenvolve e que, enquanto satisfação autoerótica, persiste como resíduo ou cicatriz do Complexo de Édipo (Freud, 1919a/1980).

Esse traço de perversão, além de encontrar como destino possível o recalque, o que o fará retornar sempre como compulsão nos sintomas, também pode vir a ser transformado em sublimação (Freud, 1919a/1980). Freud levanta a hipótese de que o recalque detenha a sublimação, essa surgindo somente quando ocorre algum processo especial.

Em "Escritores criativos e devaneio" (Freud, 1908/1980), por exemplo, ele nos indica qual seria esse processo: a transformação de algo que causa repugnância e só interessa a um sujeito em particular, em uma obra que proporciona prazer não só àquele sujeito, mas também àqueles que constituem seus leitores. Tal transformação não se daria através de um drible do recalque pelos processos primários (condensação e deslocamento), mas sim através de recursos literários (estéticos, formais, etc.). Todavia, embora essa via da sublimação se mostre importante e interessante, detenhamonos aqui apenas na fantasia enquanto relacionada ao recalque.

Freud (1919/1980a) também afirma que a fantasia surge em análise como um relato hesitante e acompanhado de vergonha e culpa, mobilizando resistência. Esse relato remete a uma cena difusa - ele não diz fato difuso - que teria se passado na primeira infância (muito cedo) e que tem um efeito traumático sobre o sujeito.

Não devemos pensar, entretanto, que a cena da fantasia necessariamente remeta a um conteúdo extremamente impressionante do ponto de vista do imaginário. Pelo contrário, Freud nos fala da fixação do sujeito a impressões corriqueiras e não excitantes para outras pessoas. Ao tentar recuperar em análise o seu surgimento, traça-se tão somente uma sequência de conexão casual que só pode interessar a um único sujeito.Vemos então que a fantasia que interessa à psicanálise não é da ordem do universal, mas sim do particular.

Stefan Zweig inicia sua novela 24 Horas na Vida de uma Mulher, pela qual Freud tinha uma predileção, abordando justamente isso, de uma maneira que só a literatura pode alcançar:

A maior parte das pessoas tem a fantasia embotada. $O$ que não as toca diretamente, o que não atinge duramente seus sentidos com sua ponta afiada quase não as excita. Mas se acontece diante de seus olhos, bem perto da sua emoção, ainda que seja algo insignificante, logo desencadeia nelas uma paixão desmedida. (Zweig, 2007, p. 11) 
Notamos que nessa instalação da neurose, de poli a uno, o sujeito encontra uma forma fixa de obter prazer autoerótico, apesar de adentrar ao amor objetal a partir do Édipo. Isso lhe permite a construção de uma unificação imaginária, pois no amor objetal as pulsões parciais aparentam uma unidade, que Freud (1917/1980) nomeia como pulsão genital. Mas, essa fixação também confere ao sujeito uma unicidade, pois esse traço de perversão, só acessível na fantasia, rege o posicionamento do sujeito em todas as suas relações interpessoais, nas quais ele repete o que Freud (1921/1980) chama de clichê estereotípico: a sua forma particular de se conduzir na vida erótica. Trata-se, então, de uma marca desse sujeito, daquilo que o singulariza.

Nessas considerações de Freud, ainda, chama a atenção o fato de a fantasia portar um paradoxo: gera prazer, mas é também repugnante. Dito de outro modo: na fantasia o prazer está articulado ao desprazer.

No que diz respeito a essa cena difusa, ainda, na experiência analítica pode-se observar que o analisando não relata a sua fantasia não porque não quer, mas porque esbarra em uma impossibilidade advinda da ação do recalque sobre o desejo. Assim, a fantasia não deve ser abordada apenas como um devaneio inconfessável, mas antes como uma reconstrução em análise que cerceia o desejo, passando por uma tentativa do sujeito de colocar na cadeia de significantes o que se apresenta como uma cena difusa.

É justamente nessa passagem ao significante que o recalque atua. Basta nos lembrarmos do esquecimento que Freud (1901/1980) analisa no primeiro capítulo de "Psicopatologia da vida cotidiana", mostrando-nos claramente que o recalque não atua sobre a imagem, uma vez que é um significante que é esquecido (Signorelli), ao mesmo tempo em que a imagem dos afrescos desse pintor se vivifica na memória de Freud. Nesse sentido, nessa reconstrução, o que está disponível ao sujeito a princípio é uma imagem ou cena, que precisa vir a ser parcialmente sabida, na cadeia de significantes, durante o trabalho analítico.

Dessa forma, notamos que a fantasia é estruturante na neurose, mas se apresenta ao neurótico como cena difusa e paradoxal. Nesse sentido, Freud salienta que, em sua experiência clínica com neuróticos, ele é forçado a admitir que "essas fantasias subsistem à parte do resto do conteúdo de uma neurose e não encontram lugar adequado na sua estrutura." (1919/1980a, p. 230). Assim, revela-se mais uma característica importante da fantasia, qual seja: ela é uma estranha para o neurótico. Isso não é sem importância, na medida em que o estranho é aquilo que nos é mais familiar (Freud, 1919/1980b). Na fantasia o sujeito está dividido, pois se encontra diante de algo que o concerne, mas que ele vê como estrangeiro.

É fundamental levar em conta, diante disso, que a fantasia não pode ser simplesmente narrada, mas precisa ser reconstruída na passagem da cena ao significante, do difuso à estrutura, passagem essa sempre incompleta, nunca totalmente satisfatória. 
Nessa reconstrução, Freud (1919/1980a) nos mostra que a organização sintática e gramatical, que aparece no discurso do analisando ao abordar a fantasia, sofre transformações no que diz respeito à relação com o autor, o objeto, o conteúdo e o significado. Ao se dedicar à descrição de como isso ocorre nas fantasias de espancamento das meninas, ele notou a existência de três tempos, quais sejam:

1. "Uma criança é espancada": trata-se da primeira emergência da cena difusa em forma de relato. Nota-se na frase que a criança espancada jamais é o próprio analisando/autor, o que leva Freud a afirmar que não se trata de uma cena masoquista. Embora a identidade de quem bate seja inicialmente obscura, sempre revela-se como um adulto, geralmente o pai da criança.

2. "Estou sendo espancada pelo meu pai.": nesse momento do relato, a criança espancada coincide com o analisando/autor, o que leva Freud a tomar esse tempo como a emergência do masoquismo. $\mathrm{O}$ adulto que bate permanece o mesmo do primeiro tempo. Trata-se de uma cena que jamais teve existência real, nunca consciente, ou seja, é uma construção da análise, que ele qualifica como necessária.

3. "Provavelmente estou olhando.": o adulto que bate e a criança espancada são substituídos por equivalentes e o analisando/autor aparece apenas no lugar de quem olha, não coincidindo com a criança espancada. Há a presença de excitação sexual masturbatória e de um caráter sádico manifesto.

Nesse momento de sua obra, Freud (1919/1980a) considera o masoquismo, que emerge no segundo tempo da fantasia, como um substituto de um sadismo primário, movido pelos ciúmes advindos dos amores incestuosos da infância e recalcados durante o Complexo de Édipo. Esse sadismo ele reconhece no primeiro tempo devido ao fato de nele outra criança estar sendo espancada. Assim, embora no segundo tempo a fantasia seja declaradamente masoquista, ela substitui e realiza, sem realizar, o sadismo que foi recalcado. Destaco aqui, então, mais uma característica importante da fantasia: ela realiza, sem realizar, um desejo.

Em relação à terceira fase da fantasia - "Provavelmente estou olhando" - Freud (1919/1980a) ressalta que o analisando/autor aparece quase como um espectador. Quase porque ele mais uma vez obtém um prazer sádico ao ver outra criança, de quem ele provavelmente tem ciúmes, sendo espancada pelo seu pai ou um substituto. Mas, é preciso considerar que essa outra criança deve ser tomada como seu duplo, pois o substitui na configuração da cena do tempo anterior, o que torna a satisfação nesse terceiro tempo da fantasia também essencialmente masoquista (Freud, 1919/1980a). 
Vemos então que Freud, ao procurar localizar o sadismo e o masoquismo nos três tempos da fantasia, acaba por encontrá-los praticamente nas três cenas. Quanto a isso, torna-se necessário dar um pequeno salto aqui, pois, apesar de Freud considerar nesse momento que o masoquismo é uma sadicização de si mesmo, cinco anos depois, em "O problema econômico do masoquismo" (Freud, 1924/1980), ele inverte essa proposta, afirmando a existência de um masoquismo erógeno ou primário, em que a dor e o sofrimento são fins em si mesmos. Trata-se de uma concepção já pautada em sua descoberta da pulsão de morte, o "Além do princípio do prazer" (Freud, 1920/1980). Nessa nova concepção, o sadismo surge a partir de uma inversão da organização sexual autoerótica primordial (masoquista) e posteriormente, em virtude do recalque, retorna ao sujeito enquanto masoquismo secundário.

Dessa forma, levando em conta esse passo a mais de Freud, podemos dizer que a fantasia é essencialmente masoquista, envolvendo o corpo do sujeito em uma cena de sofrimento prazeroso e de submissão ao desejo do Outro. Eis o incêndio da alma, em que o ser periga...

Notamos, na experiência analítica, que o analisando só pode, via de regra, fazer essa passagem da cena difusa para a cadeia de significantes na ordem inversa da apresentada por Freud, ou seja, por retroação. Isso porque, ao pensarmos o início do relato no terceiro tempo freudiano, configura-se um distanciamento do analisando/autor, pois ele se apresenta como narrador onisciente. Configura-se também um disfarce, uma vez que há a substituição por seu duplo, ou seja, a outra criança. Todavia, nessa estrutura de ficção, a verdade se mostra.

Esses distanciamentos e disfarces caem no segundo tempo, que se configura como um momento de virada, de torção, pois o que aparecia lá, no outro, aparece aqui, no analisando/autor/criança espancada. É uma construção da análise, necessária e a mais importante, ressalta Freud (1919a/1980). É o momento de evidência do masoquismo, de uma relação prazerosa de submissão ao desejo do Outro, o que não é fácil para o analisando enfrentar.

Já no primeiro tempo, chama a atenção o emprego do sujeito impessoal na frase, o que pode aparentar um distanciamento, se acompanhamos os tempos na ordem proposta por Freud. É claro que a frase "Uma criança é espancada" é pretensamente enunciada de fora da cena relatada. Ela pode ser lida, porém, como produto de uma construção que evidencia que o sujeito encontra-se esquartejado em cada canto, ou seja, ele está em quem apanha (o que se evidenciou no segundo tempo), em quem bate (o sadismo manifesto do terceiro tempo) e em quem olha (o que se evidencia só agora, de fato, pelo uso do impessoal).

Não é à toa que a posição de quem olha pode ser a última a ser construída, uma vez que essa posição requer uma torção e um encontro das duas pontas da fita da fantasia construída durante o percurso do sujeito ao 
longo desse tempo.Tal encontro permite ao sujeito reconhecer que não há dentro e fora, isto é, que aquele que está lá, apanhando e/ou batendo, está também aqui, olhando. Olhar do lugar do qual se é visto não é qualquer coisa quando se trata de uma análise. É desse lugar que podemos nos dar conta da cena fantasmática e teorizar sobre o que nos é fundamental.

A palavra teoria encontra a sua origem etimológica no grego theóría, que significa ação de observar, examinar; estudo ou conhecimento devido a um raciocínio especulativo. $\mathrm{O}$ antepositivo teor remete a contemplar, olhar com interesse, considerar com a inteligência, derivando-se de théa, que significa espetáculo, vista, visão (Houaiss, 2001).

Quanto a isso, é interessante encontrar o seguinte: a palavra "teórica" é um anagrama da palavra "erótica". Não seria justamente isso que está em jogo nessa reconstrução em análise de que nos fala Freud? Será que uma análise não caminha rumo a uma abordagem teórica, uma contemplação ativa que constrói aquilo que se vê, da forma de um sujeito conduzir-se na vida erótica?

Depois desse breve percurso por Freud, e da irrupção dessas questões, a seguir serão trazidas algumas das considerações de Lacan sobre a fantasia, pautadas principalmente nas aulas iniciais de seu seminário "La logique du fantasme" (Lacan, 1966-1967), mas também em alguns recortes de vários momentos de seu ensino que referem a esse tema.

\section{Na teia do real}

No seminário "La logique du fantasme", ministrado entre os anos de 1966 e 1967, podemos acompanhar Lacan em sua pesquisa que gira ao redor da articulação lógica da fantasia, buscando relacionar a sua estrutura à do significante, observando o universo do discurso a partir da lógica. Para isso, ele se pauta tanto na relação da fantasia com a escrita quanto na relação do pensamento com a linguagem e o inconsciente, relação essa fundada no fato de o sujeito estar barrado daquilo que o constitui, ou seja, o significante.

Lacan (1966-1967) nos adverte para o fato de a fantasia, comumente tomada na psicanálise a partir do registro do imaginário, ser por ele abordada em relação a uma estrutura, ou seja, em relação à lógica. A seu ver, não há antinomia entre a lógica e a fantasia, já que há uma lógica da fantasia, que ele escreve através do seguinte matema:

$$
\$ \diamond \mathrm{a}
$$

Desmembrando um pouco esse matema, encontramos à direita o "objeto a" que possui um valor lógico, ou seja, só adquire valor em uma relação. Não se trata, então, do imaginário a respeito do objeto (bom, mau, 
parcial, persecutório, etc.), mas sim daquilo que deve ser situado no campo do Outro como o que lhe falta. Trata-se aqui da constatação de que o universo do discurso não abarca todo o real, ou seja, há a castração do Outro.

Façamos um breve parêntese aqui para lembrar que, a esse respeito, Lacan já vem discorrendo desde o seminário "As relações de objeto" (19561957/1995), ocasião em que afirma que, embora na vertente anglo-saxã o objeto apareça como central, é a falta de objeto que interessa à psicanálise, uma vez que ela é a própria mola da relação do sujeito com o mundo.

Quanto ao articulador lógico punção $(\diamond)$, que se localiza no centro do matema, Lacan (1966-1967) aponta que ele pode ser lido de duas maneiras. Uma delas se obtém a partir de um corte vertical, decompondo-o nos símbolos matemáticos 〈 (menor que) e > (maior que). A outra, à qual ele parece mais se ater nesse seminário, é obtida a partir de um corte horizontal, decompondo esse articulador nos seguintes símbolos da Lógica Proposicional (Detlefsen, McCarty, \& Bacon, 2004):^ (conjunção) e \ (disjunção inclusiva).

A disjunção pode ser descrita como a transformação de duas frases em uma através do conectivo "ou" (Detlefsen, McCarty, \& Bacon, 2004), de forma a não restar nem uma, nem outra das frases anteriores, mas apenas um composto. No caso específico da disjunção inclusiva, referida também pelo termo latino vel, um composto é verdadeiro se, e só se, pelo menos uma de suas frases componentes o for. Já a conjunção pode ser considerada como um "e", que também permite formar um composto, embora preservando cada uma das frases separadamente (Detlefsen, McCarty, \& Bacon, 2004).

Vemos, então, que esta decomposição do articulador punção, por Lacan (1966-1967), revela o seu esforço por articular o sujeito (\$) ao objeto (a) de uma forma flexível (Gerbase, 1987), impedindo uma confusão entre ambos. Trata-se de uma maneira de escrever tanto "ou o sujeito ou o objeto" (disjunção inclusiva), quanto "o sujeito e o objeto" (conjunção). Vejamos o porquê disso.

O "objeto a", como vimos, adquire valor em uma relação com a falta no Outro. Isso porque ele é suposto como o objeto que este demanda para satisfazer seu desejo, ou seja, o objeto que poderia completá-lo. Assim,"nos efeitos que respondem num sujeito a uma determinada demanda, vêm interferir os de uma posição em relação ao outro" (Lacan, 1958/1998, p. 643). Trata-se, portanto, do objeto que saldaria a dívida da linguagem, que instituiu o sujeito, pois "alguma coisa tem que ser paga àquele que introduz seu signo." (Lacan, 1969-1970/1992, p. 149).

O atendimento a essa demanda do Outro implica em uma relação do sujeito com o "objeto a" através da operação de disjunção inclusiva, uma vez que se há a presença do "objeto a", o sujeito fica eclipsado, já que essa operação institui um "ou um ou outro". Podemos dizer que nessa operação o resultado é um composto, um Outro completo, que incorpora o objeto e anula o sujeito, configurando-se assim um "nem sujeito nem objeto". 
Podemos dizer também que a fantasia realiza a posição de objeto para fazer frente ao desamparo que a falta no Outro produz no sujeito, o qual não quer saber sobre a resposta negativa que já obteve para a pergunta "Pode o Outro me perder?" (Lacan, 1964/1998). Tal resposta ele obteve no próprio ato que inaugurou a sua existência, pautada em uma expulsão primordial que, embora o tenha exposto ao desamparo, também o livrou de permanecer como aquilo que resolveria a inveja do pênis de sua mãe (Pommier, 2005), pois o tornaria a encarnação do falo perdido de Osíris ${ }^{3}$ embalsamado (Lacan, 1958/1998).

Para tentar se garantir, o sujeito precisa oferecer-se como objeto, atendendo a demanda do Outro e supostamente saldando sua dívida para com ele. Mas, ele também precisa não quitar essa dívida de vez, caso contrário ele desaparece enquanto sujeito, ficando restrito a um prolongamento narcísico do Outro. É isso que a introdução da operação da conjunção permite, pois de alguma maneira se assegura uma forma de ser e de concomitantemente não ser o "objeto a", uma reversibilidade. Freud (1919/1980), como vimos, já sinalizava isso ao afirmar que a fantasia realiza, sem realizar, o desejo. Vemos, então, no matema da fantasia a escrita desse paradoxo: o sujeito realiza $(\vee)$, sem realizar $(\wedge)$, a sua entrega ao Outro como objeto.

Lacan (1966-1967), dando mais um passo, acrescenta que é necessário, porém, que algo esteja pronto para portar a fantasia, que haja um prêt-à-porter. Esclarecendo um pouco isso, ele afirma que é necessária uma existência de fato (a do vivente) para a possibilidade de uma existência lógica (a do falante). Vemos que ele está aí introduzindo duas das categorias da Lógica Modal: o necessário (sempre é) e o possível (às vezes é) ${ }^{4}$.

Na Lógica Modal, ainda, o símbolo $\diamond$ significa"é possível que",o que nos revela algo importante visado por Lacan com a criação do matema da fantasia: deixar claro que ela se inscreve logicamente enquanto possibilidade.

Podemos dizer que o necessário, embora condição para, não garante o possível, ou seja, nem sempre uma existência lógica advém onde era uma existência de fato. Porém, pelo contrário, o possível atesta a existência do necessário, o qual é deduzido logicamente, por retroação. Trata-se de uma implicação existencial, em que o necessário aparece como aquilo que teria estado lá, o que remete a um tempo lógico e não cronológico.

Podemos visualizar essas articulações, de maneira condensada, na seguinte frase de Lacan (1966-1967) em “La logique du fantasme":"un sujet emerge, le sujet barré, comme quelque chose qui vient d'um lieu ou il est suposé inscrit, dans um autre lieu où il va s'inscrire à nouveau" (p. 18)

3 Segundo o mito, Osíris foi esquartejado por seu irmão e, embora seus pedaços tenham sido juntados novamente, seu falo se perdeu e nunca mais foi encontrado.

4 As demais categorias são: o contingente (às vezes não é) e o impossível (nunca é).

5 "um sujeito emerge, o sujeito barrado, como qualquer coisa que vem de um lugar onde ele está supostamente inscrito, para outro lugar em que ele vai se inscrever novamente." (p. 18, tradução nossa). 
Dito de outro modo: há uma existência de fato, aquela que sempre é quando se trata do sujeito, que é suposta como antecedendo logicamente tudo aquilo que concebemos a partir da operação da identificação especular e das vicissitudes edípicas. Essas últimas inauguram a existência de um sujeito barrado (\$), regida pela lógica do significante, aquela que às vezes é e que sucede logicamente o sujeito que teria estado lá, em sua inefável e estúpida existência.

Tal anterioridade lógica da existência de fato, Lacan (1958/1998) representa, em "Uma questão preliminar a todo tratamento possível da psicose", por um S sem a barra (vide esquema R) e em "Posição do Inconsciente" (Lacan, 1964/1998) pelo mito da Homelete, que é imortal e assexuada, ou seja, ainda não padece do significante, embora tenha dele precisado já na operação da quebra dos ovos.

Esse necessário da existência de fato pode ser tomado, então, como o prét-à-porter, o que estava ali de pronto para falar (Lacan,1966-1967). Para abordá-lo, Lacan (1966-1967) se refere aos objetos pulsionais: o seio, as fezes, o olhar e a voz. Reencontramos aqui o traço de perversão, advindo das pulsões parciais, a que se fixa o sujeito na fantasia, conforme trazido por Freud (1919/1980a). O seguinte trecho de Lacan, retirado do seminário sobre os quatro conceitos fundamentais, é esclarecedor quanto a isso:

a importância que o sujeito dá à sua própria esquize está ligada ao que a determina - isto é, um objeto privilegiado, surgido de alguma separação primitiva, de alguma automutilação induzida pela aproximação mesma do real, cujo nome, em nossa álgebra, é objeto $a$. (Lacan, 1964, p. 83).

Enquanto destacáveis do corpo, os objetos pulsionais podem ser intercambiáveis, entrarem em uma economia de troca com o Outro. Eles são aquilo que do corpo se presta a uma existência lógica, dentro da lógica do significante (Lacan, 1966-1967), que é uma lógica que se constitui por relações que criam os próprios elementos que nela se relacionam.

Assim, na existência lógica, não é o corpo todo que se presta à relação com o Outro, já que apenas um objeto é destacado desse corpo e doado ao Outro, na busca de completá-lo.Trata-se do "objeto a",através do qual o sujeito se preserva de uma doação integral que o eclipsaria enquanto sujeito. Há assim dois momentos lógicos, que serão nomeados aqui como destacamento e doação, nos quais nos deteremos de agora em diante.

A operação de destacamento, de extração de um objeto pulsional, parece constituir o necessário a que Lacan remete, o prêt-à-porter a fantasia. Trata-se de uma primeira operação de corte, sem dúvida. Mas, apenas esse corte não constitui o "objeto a", uma vez que a sua constituição requer também a doação dessa parte do corpo ao Outro, o que pode ocorrer ou não. Essa doação é o início de uma existência lógica, já pautada pelo signi- 
ficante, dentro de uma relação onde surge o valor desse signo cristalizado do desejo do Outro que é o "objeto a".

É o que Lacan (1961) nos mostra em seu seminário sobre a identificação, fazendo uso da figura topológica toro em que as voltas, sucessivas e em espiral, do traço unário (o que foi destacado) configuram um círculo pleno (da demanda) ao redor de um círculo vazio (do desejo), esse último nunca contado pelo sujeito. Além disso, Lacan (1961/2003) nos mostra que o círculo vazio do toro do sujeito corresponde ao círculo pleno do toro do Outro, assinalando com isso a relação entre o desejo do primeiro e as demandas do segundo. Assim, o desejo do sujeito é o desejo do Outro, que se apresenta como uma enunciação onipresente e marcada nos enunciados que lhe dão corpo como demanda. Quanto a isso, Lacan já afirmava em "A direção do tratamento e os princípios de seu poder":

É, pois, a posição do neurótico em relação ao desejo - digamos, para encurtar, à fantasia - que vem marcar com sua presença a resposta do sujeito à demanda... Mas a fantasia só chega a isso por se encontrar na via de retorno de um circuito mais amplo, aquele que, levando a demanda aos limites do ser, faz com que o sujeito se interrogue sobre a falta em que ele aparece a si mesmo como desejo. (Lacan, 1958/1998, p. 644)

Tudo isso nos conduz a uma importante afirmação de Lacan (19661967) em "La logique du fantasme": o "objeto a" resulta de duas operações lógicas. A primeira delas é a alienação, bastante trabalhada por ele no seminário sobre os quatro conceitos fundamentais:

O vel da alienação se define por uma escolha cujas propriedades dependem do seguinte: que há, na reunião, um elemento que comporta que, qualquer que seja a escolha que se opere, há por conseqüência um nem um, nem outro. A escolha aí é apenas a de saber se a gente pretende guardar uma das partes, a outra desaparecendo em cada caso." (Lacan, 1964/1988, p. 200, itálicos nossos)

Notamos nesse trecho que, para abordar a alienação, Lacan (1964/1988) também lança mão da operação de reunião (ou soma lógica), oriunda da Teoria dos Conjuntos, equivalendo-a à disjunção inclusiva $\left({ }^{\vee}\right)$ da Lógica Proposicional. Através de um diagrama de Euler-Venn, ele representa a alienação, mostrando-nos a escolha forçada do sujeito (conjunto $A$ ) diante do desejo do Outro (conjunto B), ou seja, uma escolha que conduz o sujeito ao eclipse, como comentado há pouco. 


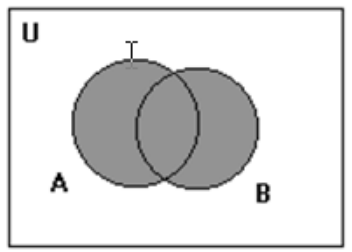

Figura 1. A reunião ou soma lógica.

Já a conjunção $(\wedge)$ entre $\$$ e "a" se revela, na Teoria dos Conjuntos, como uma intersecção (ou produto lógico). No diagrama abaixo notamos como a relação dos dois conjuntos não comporta o eclipse do sujeito (conjunto $A$ ), pois restringe a sua relação com o Outro (conjunto $B$ ) apenas a um ponto de intersecção:

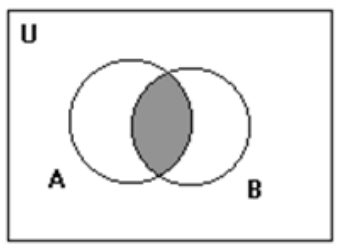

Figura 2. A intersecção ou produto lógico.

Recorrendo ao Teorema de Morgan ${ }^{6}$, Lacan (1966-1967) nos mostra que, através da quebra da barra da negação introduzida nas operações lógicas de reunião e intersecção, é possível transformar a reunião entre dois conjuntos em uma intersecção entre esses mesmos conjuntos. Assim, há como passar da alienação para uma outra forma de relação do sujeito com o Outro: a separação, que permite a preservação do sujeito.

Isso é desenvolvido por Lacan (1964) em "Posição do Inconsciente", quando ele resgata a origem etimológica do verbo separar, que advém do latim separare (desunir, dividir, apartar). Nessa ocasião, ele joga com esse termo em latim, transformando-o em se parere (se parir, se produzir). Podemos dizer que a operação da separação marca uma (de)cisão do sujeito por se articular ao Outro sacrificando não todo o seu ser, mas apenas uma parte de seu corpo, ou seja, o "objeto a".

A lógica da fantasia, assim, comporta a alienação e a separação, configurando-se como uma escrita que se repete porque é a própria lógica de um sujeito, isto é, a sua invenção para se haver com a castração do Outro sem, no entanto, a ele se entregar ou dele se apartar completamente.

6 Augustus de Morgan (1806-1871) introduziu os fundamentos da Lógica Simbólica ou Moderna, formulando leis que introduzem a negação como essencial na lógica. Desenvolveu um par de regras complementares usadas para converter a operação OU em E e vice versa. 
Embora Lacan (1966-1967) nos traga um matema que vale para toda e qualquer fantasia na neurose, é claro que a maneira como o sujeito se doa e se furta, o seu clichê estereotípico ou a sua erótica (Freud, 1912/1980), é da ordem do singular, precisando ser reconstruída em análise, como já apontava Freud (1919a/1980).

Entretanto, como afirma Lacan (1966-1967), essa escrita se encontra recalcada, ou seja, ela não pode ser lida porque não significa nada para o leitor. Ela se apresenta tal qual os hieróglifos antes de sua decifração. Foi necessário, como se sabe, um trabalho de passagem da imagem ao significante para a sua decifração. É esse também o trabalho do sujeito em uma psicanálise. Mas, nessa tessitura, nem tudo passa às palavras e ele é fadado insistentemente a dar de encontro com aquilo que não conhece: a teia do real que ninguém tece.

\section{Some considerations about fantasy in Freud and Lacan}

Abstract: This article discuss some considerations by Freud and Lacan about the fantasy, pointing out its origin and function for the subject. For such reason, it analyzes the three times of fantasy postulated by Freud and the two logical operations, which constitute the articulator between the subject and the "object a", present in the matheme of fantasy elaborated by Lacan, namely: the alienation and the separation.

Keywords: Fantasy. Freud, Sigmund, 1856-1939. Lacan, Jacques, 1901-1981.

\section{Quelques considérations sur le fantasme dans Freud et Lacan}

Résumé: Cet article discute quelques considérations de Freud et Lacan sur le fantasme, en insistant sur sa genèse et fonction pour le sujet. Pour ça, reprend les trois temps du fantasme établi par Freud et les deux opérations logiques, qui constituent l'articulateur entre le sujet et l'objet a, présents dans le matema du fantasme élaboré par Lacan, à savoir:I'aliénation et la séparation.

Mots-clés: Fantasme, Freud, Sigmund, 1856-1939. Lacan, Jacques, 1901-1981. 


\section{Algunas consideraciones sobre el fantasma en Freud y Lacan}

Resumen: Este artículo discute algunas consideraciones acerca del fantasma en Freud y Lacan, destacando su génesis y función para el sujeto. Para eso, analisa los tres tiempos del fantasma propuestos por Freud y las dos operaciones lógicas, que componen el articulador entre el sujeto y el objeto, presentes en el matema del fantasma desarrollado por Lacan, es decir, la alienación y la separación.

Palabras-clave: Fantasía. Freud, Sigmund, 1856-1939. Lacan, Jacques, 1901-1981.

\section{Referências}

Detlefsen, M., Mccarty, D. C., \& Bacon, J. B. (2004). Glossário de lógica. Lisboa: Edições 70.

Freud, S. (1980). A psicopatologia da vida cotidiana. In S. Freud, Edição standard brasileira das obras psicológicas completas de Sigmund Freud (J. Salomão, trad., Vol. 6). Rio de Janeiro: Imago. (Trabalho original publicado em 1901)

Freud, S. (1980) Três ensaios sobre a teoria da sexualidade. In S. Freud, Edição standard brasileira das obras psicológicas completas de Sigmund Freud (J. Salomão, trad., Vol. 7, pp. 129-256). Rio de Janeiro: Imago. (Trabalho original publicado em 1905)

Freud, S. (1980). Escritores criativos e devaneio. In S. Freud, Edição standard brasileira das obras psicológicas completas de Sigmund Freud (J. Salomão, trad., Vol. 9, pp. 149-161). Rio de Janeiro: Imago. (Trabalho original publicado em 1908)

Freud, S. (1980). A dinâmica da transferência. In S. Freud, Edição standard brasileira das obras psicológicas completas de Sigmund Freud (J. Salomão, trad., Vol. 12, pp. 133-148). Rio de Janeiro: Imago. (Trabalho original publicado em 1912)

Freud, S. (1980). Conferências introdutórias sobre psicanálise - Parte III. In S. Freud, Edição standard brasileira das obras psicológicas completas de Sigmund Freud (J. Salomão, trad., Vol. 16). Rio de Janeiro: Imago. (Trabalho original publicado em 1917)

Freud, S. (1980). Uma criança é espancada - uma contribuição ao estudo da origem das perversões sexuais. In S. Freud, Edição standard brasileira das obras psicológicas completas de Sigmund Freud (J. Salomão, trad., Vol. 17, pp. 225-253). Rio de Janeiro: Imago. (Trabalho original publicado em 1919a)

Freud, S. (1980). O estranho. In S. Freud, Edição standard brasileira das obras psicológicas completas de Sigmund Freud (J. Salomão, trad., Vol. 18, pp. 275-314). Rio de Janeiro: Imago. (Trabalho original publicado em 1919b)

Freud, S. (1980). Além do princípio do prazer. In S. Freud, Edição standard brasileira das obras psicológicas completas de Sigmund Freud (J. Salomão, trad., Vol. 18, pp. 17-90). Rio de Janeiro: Imago. (Trabalho original publicado em 1920) 
Freud, S. (1980). O problema econômico do masoquismo. In S. Freud, Edição standard brasileira das obras psicológicas completas de Sigmund Freud (J. Salomão, trad., Vol. 19, pp. 199-216). Rio de Janeiro: Imago. (Trabalho original publicado em 1924)

Gerbase, J. (1987). Fantasia ou fantasma. Falo - Revista Brasileira do Campo Freudiano, (1), 45-50.

Houaiss, A. (2001). Dicionário eletrônico da Língua Portuguesa. São Paulo: Objetiva.

Lacan, J. (1966-1967). Le séminaire de Jacques Lacan. Livre 14: la logique du fantasme. Seminário inédito.

Lacan, J. (1988). Oseminário de Jacques Lacan. Livro 11: os quatro conceitos fundamentais da psicanálise. Rio de Janeiro: Jorge Zahar. (Seminário ministrado nos anos de 1964)

Lacan, J. (1992). O seminário de Jacques Lacan. Livro 17: o avesso da psicanálise. Rio de Janeiro: Jorge Zahar. (Seminário ministrado nos anos de 1969-1970)

Lacan, J. (1998). O seminário de Jacques Lacan. Livro 4: as relações de objeto. Rio de Janeiro: Jorge Zahar. (Seminário ministrado nos anos de 1956-1957)

Lacan, J. (1998). De uma questão preliminar a todo tratamento possível da psicose. In J. Lacan, Escritos (pp. 537-590). Rio de Janeiro: Jorge Zahar. (Trabalho original publicado em 1958)

Lacan, J. (1998). A direção do tratamento e os princípios de seu poder. In J. Lacan, Escritos (pp. 591-652). Rio de Janeiro: Jorge Zahar. (Trabalho original publicado em 1958)

Lacan, J. (1998). Posição do inconsciente. In J. Lacan, Escritos (pp. 843-864). Rio de Janeiro: Jorge Zahar. (Trabalho original publicado em 1964)

Lacan, J. (2003). A identificação. Recife: Centro de Estudos Freudianos do Recife. (Seminário ministrado no ano de 1961)

Pommier, G. (2005). Qué es lo "real" - ensayo psicoanalítico. Buenos Aires: Nueva Visión.

Zweig, S. (2007). 24 horas na vida de uma mulher. Porto Alegre: L\&PM.

Alessandra Fernandes Carreira, Doutora em Psicologia pela Universidade de São Paulo, Professora Titular da Universidade de Ribeirão Preto - Curso de Psicologia, Pós-Doutoranda pelo Instituto de Estudos da Linguagem - Universidade Estadual de Campinas. Endereço para correspondência: Avenida Costábile Romano, 2201, Ribeirão Preto, SP, Brasil.CEP 14021-220.Endereço eletrônico: afcarreira@gmail.com

Recebido em: 6/08/2008

Aceito em: 8/12/2008 
